\title{
Making sense of algorithms: Relational perception of contact tracing and risk assessment during COVID-I 9
}

Big Data \& Society

January-June: $1-13$

(C) The Author(s) 2021

Article reuse guidelines:

sagepub.com/journals-permissions DOI: 10.1 I77/205395|721995218 journals.sagepub.com/home/bds

@SAGE

\author{
Chuncheng Liu $\mathbb{D}$ and Ross Graham (D)
}

\begin{abstract}
Governments and citizens of nearly every nation have been compelled to respond to COVID-19. Many measures have been adopted, including contact tracing and risk assessment algorithms, whereby citizen whereabouts are monitored to trace contact with other infectious individuals in order to generate a risk status via algorithmic evaluation. Based on 38 in-depth interviews, we investigate how people make sense of Health Code (jiankangma), the Chinese contact tracing and risk assessment algorithmic sociotechnical assemblage. We probe how people accept or resist Health Code by examining their ongoing, dynamic, and relational interactions with it. Participants display a rich variety of attitudes toward privacy and surveillance, ranging from fatalism to the possibility of privacy to trade-offs for surveillance in exchange for public health, which is mediated by the perceived effectiveness of Health Code and changing views on the intentions of institutions who deploy it. We show how perceived competency varies not just on how well the technology works, but on the social and cultural enforcement of various non-technical aspects like quarantine, citizen data inputs, and cell reception. Furthermore, we illustrate how perceptions of Health Code are nested in people's broader interpretations of disease control at the national and global level, and unexpectedly strengthen the Chinese authority's legitimacy. None of the Chinese public, Health Code, or people's perceptions toward Health Code are predetermined, fixed, or categorically consistent, but are co-constitutive and dynamic over time. We conclude with a theorization of a relational perception and methodological reflections to study algorithmic sociotechnical assemblages beyond COVID-19.
\end{abstract}

\section{Keywords}

Sociotechnical assemblage, algorithm, contact tracing, surveillance, COVID-I9

\section{Introduction}

The relationship between algorithms and individuals is dynamic and tempestuous in the era of Big Data. Algorithms and related technologies have been employed for multiple social purposes, including but not limited to public health efforts to fight COVID19 (French and Monahan, 2020; Kitchin, 2020). Accordingly, an enormous commercial market has emerged for data about individuals (Fourcade and Healy, 2017; Zuboff, 2019). Additionally, state institutions have increased appetite for this data, which is useful for various algorithmic governance measures (Liu, 2019; Rona-Tas, 2020). Today, issues regarding trust, privacy, and surveillance dominate the ethical and social debates on these technologies. Examples include the fairest ownership models for data on individuals, effective trade-offs between privacy and safety, and the appropriateness of deploying algorithms with inscrutable, or black-boxed, statistical reasoning (Eubanks, 2018; Mittelstadt et al., 2016; Pasquale, 2015; Zuboff, 2019).

Scholarship in this area often focuses upon the technical function of the algorithm, attempting to open the

\footnotetext{
Department of Sociology, University of California San Diego, La Jolla, USA

Both authors contributed equally to this work.

\section{Corresponding author:}

Chuncheng Liu, Department of Sociology, University of California San Diego, La Jolla, CA 92093-002I, USA.

Email: chchliu@ucsd.edu
} 
"black box" (Pasquale, 2015). The implicit logic of these studies is that, by understanding what the algorithm does in terms of information processing, it can be altered and tweaked to mitigate undesirable social outcomes or enhance desirable ones. But algorithms are not merely lines of code or sequences of automated, executable digital rules. They are not solely digital or technical objects. Rather, algorithms are created by people, often within institutions, and constantly undergo change and development (Kitchin, 2017; Liu, 2020; Seaver, 2017). They are designed toward certain ends these ends can shift over time in response to social, economic, cultural, or political phenomena, thereby affecting the algorithms function. Moreover, the ends of one algorithm can conflict with and be affected by other algorithmic systems targeting different ends, as well as the goals or values of other people and groups. These incentives and influences partially shape the digital operations of the algorithm. Shoshanna Zuboff, for instance, advocates thinking of algorithms as both products and expressions of the institutional logics that afforded their creation - this amounts primarily to a "logic of accumulation," whereby "hyperscale assemblages of objective and subjective data about individuals" are used for "knowing, controlling and modifying behavior to produce new varieties of commodification, monetization and control" (Zuboff, 2019). This kind of analytical emphasis remains "technology-side" - namely large technology corporations like Google, Facebook, and Alibaba. The general public, despite being the locus of socio-ethical concerns, are homogenously framed as pliable, acquiescent, or unwitting subjects to corporate agendas. By extension, analysis of the needs and perspectives of the public on issues like privacy or surveillance protections are similarly group-based, static, and homogenous.

But the meaning of technologies is constantly formed and reformed in response to how varied individuals, groups, and institutions interact with them over time (Knorr Cetina, 1999). The designers, creators, and owners of a technology offer only a partial account of the meaning and function a technology has in society, and algorithms are no different. They change over time through dynamic interplay not only with the data they receive and the coders making updates and edits but also the heterogeneity of individuals who use it (Amelang and Bauer, 2019; Brayne and Christin, 2020). Indeed, in recent years, public cognizance of algorithms has advanced immensely as they interact with them increasingly regularly, in a greater variety of contexts and with a diversifying array of practices. An operational algorithm is intrinsically entangled with the individuals engaging with it, and this engagement varies widely. Therefore, how people engage with an algorithm is not merely an "input" rather, it is a constituent part of the algorithm itself (Introna, 2016; Kitchin, 2017). Furthermore, these interactions are shaped in an ongoing fashion by the perception each individual has of the algorithm, as their perspective guides their interpretation of the technology and their behavior while using it. This concept has been coined as the "algorithmic imaginary" - "the way in which people imagine, perceive and experience algorithms and what these imaginations make possible" (Bucher, 2017: 13).

Accordingly, critical algorithm scholars suggest that apt social or cultural investigations of algorithms must treat them as dynamic and unstable objects, ones that are enacted not only through an automated digital process but by the perceptions, imaginaries, and practices of the individuals who interact with them in their everyday lives (Christin, 2017; Introna, 2016; Liu, 2020; Seaver, 2017). This requires "an approach to algorithms informed by their empirical profusions and practical existence in the wild - always at the boundaries of diverse communities of practice" (Seaver, 2017: 2). Algorithms, we claim, are more accurately conceptualized as sociotechnical assemblages, whereby the technology cannot be separated from the social factors that constantly mediate it. The social is heterogenous the public is not a monolithic bloc of "users" of an algorithm, but instead a diverse collection of individuals loosely bound by their distance from the algorithms technical components. We thus advocate for a relational view of the social, taking guidance from Pierre Bourdieu:

one has to avoid turning into necessary and intrinsic properties of some group...the properties which belong to this group at a given moment in time because of its position in a determinate social space and in a determinate state of the supply of possible goods and practices... one has to deal with a set of social positions which is bound by a relation of homology to a set of activities ... or of goods ... that are themselves characterized relationally. (Bourdieu, 1998: 4-5)

Angele Christin (2017) has conducted studies in this vein, addressing how people make sense of an algorithm in various contexts. Christin uncovered notable gaps between the intended and actual uses of algorithms designed for journalists and criminal court employees. She observed an iterated and unstable reformulation of the algorithms meaning, animated by ongoing critique and behavioral modification while using it. Specific, dynamic imaginaries of the algorithm were cultivated over time that were "mobilized differently to comply with or resist algorithmic technologies" (Christin, 2017: 11). In a similar 
recent study of policing and criminal courts, Brayne and Christin (2020) show how the initial justifications for using algorithms - neutrality and impartiality clash with employees who perceive a threat to their agency, expertise, and discretion. This sparked distinctive internal methods of resistance, motivating the masking and relocation of discretionary individual decisions to unseen areas of the organization. These studies highlight how understanding algorithms in social settings requires paying attention to sensemaking practices and interpretation in local context.

In this paper, we present qualitative data on the interplay of practice and sense-making by individuals using Health Code (jiankangma), the algorithmic contact tracing and risk assessment sociotechnical assemblage for COVID-19 in China. One way people make sense of Health Code is in terms of privacy. Some consider the invasion of privacy justifiable in the name of public health, while others cynically consider privacy illusory. A minority, mainly young people, find the extra violations of privacy intolerable. Individuals also understand Health Code in relation to wider technological trends. Some communicate acceptance of, and faith in, the advancing Chinese digital society and its associated benefits, generating trust in the technology. Others consider China's overall digital progress and utility to be overblown, informing skepticism of the technology. Finally, people understand Health Code with respect to its implementation. To some, the social rearrangements necessary to accommodate the sociotechnical assemblage are viewed as an effective expression of care by the state. To others, it is overwrought, disruptive, and labor-intensive when compared with other more traditional disease control methods. Individuals express concern about the accuracy of data input by citizens, as well as the normalization of the surveillance infrastructure once the pandemic is resolved.

\section{Perceiving algorithms in a pandemic}

The perceived threat algorithms pose to individuals, including notions like privacy and surveillance, has been altered by the onset of COVID-19 - for instance, citizens of various countries all show some greater willingness to forego civil liberties in order for their governments to better attend to the pandemic, civil liberties that protect digital privacy and surveillance (Alsan et al., 2020). Public health systems rely on surveillance infrastructure and risk assessment for disease detection and intervention (Armstrong, 1995; Foucault, 1990). Since pandemics like COVID-19 are intrinsically inclusive, either directly or indirectly affecting everyone (French and Monahan, 2020), public health authorities have more latitude to deploy surveillance structures than before the pandemic. A combination of measures known as contact tracing and risk assessment has become widespread as a result. Contact tracing is a public health technology that has been used to combat infectious diseases for some decades. In short, it identifies as many infected individuals as possible, in addition to individuals they have come into contact with (Center for Disease Control, 2020). This effort helps prevent disease transmission in two ways. First, by pinpointing individuals for direct interventions (e.g. quarantine). Second, by generating macro-level data from which trends can be assessed for further public health and policy interventions (Tang, 2020).

The predominant method for contact tracing for COVID-19 is algorithmic, using mainly smartphones to collect data (Collado-Borrell et al., 2020). Their ubiquity, the high likelihood that they will remain on an individual's person, and powerful inbuilt datacapture technologies make smartphones a fairly comprehensive and systematic way of collecting contact information. Data from contact tracing is processed by algorithms to provide users with risk assessment on the same digital device. For COVID-19, risk assessment refers to the risk that an individual may be infectious and, therefore, must quarantine. Real-time automated digital deployment via algorithms means contact tracing and risk assessment in COVID-19 are tightly coupled together - both the input data and the output risk status occur via the same device. Despite the public health urgency of COVID-19, some scholars still critique the notion of digital contact tracing and risk assessment, suggesting it opens the door for civil liberties violations (Bengio et al., 2020; Kitchin, 2020; Tang, 2020). This includes country-specific critiques in the United Kingdom (Edwards et al., 2020), Poland (Nielsen, 2020), and Russia (Ilyushina, 2020).

But are these potential violations of civil liberties important to users? How do individuals perceive and make sense of these measures in their everyday contexts? To investigate this, we take China as our case. China was one of the first countries to adopt contact tracing and risk assessment algorithms in the COVID-19 pandemic (Cha, 2020; Loder, 2020). This continues a pattern of acceptance by Chinese residents of surveillance that scholars have tried to explain in a few ways. Lü (2005) suggests that, culturally speaking, privacy is an instrumental good in China (i.e. its value is in service of some higher ideal), contrasting with being an intrinsic good in the West (i.e. its importance is self-justifying). As a result, it is easier for Chinese to trade-off "privacy" with other social goods such as safety (Zhang et al., 2019) or trust (Kostka, 2019). Others have suggested that the Chinese public simply responds with a sophisticated, judicious brand of 
self-censorship (Shao, 2020). This is possible due to higher knowledge of surveillance technologies in China than other nations (Liang and Chang, 2006), and high awareness of liberal data-sharing between the state and private companies producing these digital goods (Hou, 2017). The SARS (2003) and MERS (2012) outbreaks also previously inculcated infrastructure and awareness of contact tracing and risk assessment for infectious disease outbreaks (Au et al., 2020; Cha, 2020) - early evidence suggests Chinese people are generically more accepting of privacy invasions for COVID-19 too (Alsan et al., 2020). These arguments have merit but are overly generalized and static for such a large and varied polity. Channeling critical algorithm studies, we believe a fuller understanding of algorithmic sense-making necessitates examining the algorithm in dynamic interplay with the practices and perceptions of the individuals who use it during the pandemic.

China's contact tracing and risk assessment procedure employs an algorithmic sociotechnical assemblage called Health Code; both the technology and its implementation are a conjoined effort between national and local governments and two large technology companies, Alibaba and Tencent (Fang, 2020). It is run on the ubiquitous Chinese smartphones APPs WeChat (owned by Tencent), Alipay (owned by Alibaba), or on its own. While much of the personal and demographic data used for the APP is already freely available to the government (Fang, 2020), other novel data is collected passively in real-time (e.g. location) or through mandated daily user entries (e.g. health status, symptoms). By the end of March, almost all Chinese cities had their own Health Code variant. Although nationwide in terms of coverage, Health Code is not a fully centralized system. While both Tencent and Alibaba leverage a system architecture known as Elasticsearch, each city's contact tracing is slightly different. Today, a suite of national, provincial, and municipal-level systems co-exist and are used for slightly different ends. Officially, the government organizes the data into four categories: (1) personal data (name, gender, ID card number, phone number, etc.); (2) personal health data (temperature, symptoms, high-risk people contact history, etc.); (3) location data (visit history from provincial level to district level, commute history, etc.); and (4) health status data (health status, testing result, etc.).

A user is first required to verify his/her real name and finish a long survey to initiate Health Code. In some cities, facial data is also required. In addition to passive collection of a user's location, Health Code requires individuals to scan QR codes strategically placed at checkpoints in public or busy spaces, such as buses, supermarkets, or residential communities
(Liu, 2020). This data effectively traces the individual. When combined with health data, Health Code generates real-time risk status evaluations presented to the user after scanning a QR code checkpoint. Symbols of an individual's "health status" come in three colors: green, yellow, or red. Green means healthy and low risk, yellow moderate risk, and red high risk or symptomatic. Individuals must produce their color code on demand for inspectors at checkpoints. For example, in some cities, a passenger needs to scan the QR code at the door and show the driver his/her color code before boarding a bus. The immediate consequences of obtaining yellow or red Health Codes vary regionally. Generally, they include isolation or quarantine, and more rigorous health reporting until they are reclassified as green.

\section{Method}

This study used qualitative data from 38 in-depth, semi-structured interviews conducted by the first author and two research assistants from late April to late June. We used diverse channels to recruit interviewees, including social media platforms and snowballing methods for contacts of those we had already interviewed. We recruited our interviewees with a poster inviting people who had used Health Code in the past two months to discuss their experiences. To ensure we captured the breadth of people's experiences and perceptions of Health Code, we purposively diversified our sample based on gender (23 females and 15 males), location (15 provinces), age (18 to 55, mean: 29 ), and cross-city mobility during the past two months (21 traveled to other cities during the pandemic). We use pseudonyms to protect interviewees' privacy.

We conducted telephone interviews via WeChat, a popular Chinese social media APP in Mandarin Chinese. Questions regarding personal experiences of the pandemic, experiences and perceptions of Health Code, and privacy concerns were asked. While questions specifically referenced "Health Code (jiankangma)," our interviewees often discussed their experiences and perceptions of the "algorithm (suanfa)," "implementation (shishi)," "platform (pingtai)," "big data (dashuju)" of Health Code. All interviews were recorded with consent and transcribed to text for analysis. Each interview lasted from 30 to 90 minutes. In addition to interview data, we also collected policy documents, newspaper articles, and social media posts that are related to Health Code to further contextualize our study. This study was reviewed and approved by the IRB at University of California, San Diego (\#200729XX).

The first author translated the Chinese quotes to English and used MAXQDA 12 to analyze all the qualitative materials. As we aim to show a diverse range of 
sense-making processes, we used thematic analysis. We first familiarized ourselves with the data by unstructured coding and discussed the themes that emerged. We then reviewed, revised, and reclassified those unstructured codes into a structured codebook for analysis of the data. We adopted the abductive analysis approach (Timmermans and Tavory, 2012) in code and theme development. In this paper, we focused on three general themes of sense-making about Health Code: privacy, technology, and implementation. We do not claim to exhaustively present every type of sensemaking for Health Code - instead, we order our results based on perceived importance and current literature (such as the "privacy tradeoffism" subtheme) and our interviewees' responses (such as the reoccurrence of "Not (that) private" subtheme). These different themes and sub-themes do not necessarily map different kinds of people. As we will show, different themes are interconnected and often coexist in one person. Sometimes they are complementary, while other times they conflict with each other.

\section{Making sense of privacy}

\section{Privacy tradeoffism}

With only two exceptions, the majority of our interviewees agree that contact tracing surveillance and risk assessment are necessary. As the country first-hit by the COVID-19 pandemic, and having experienced prior social panic during the SARS and epidemics, the Chinese public is generally cooperative with the state's strict disease control strategy (Au et al., 2020). Most people understand the potential privacy invasions of Health Code, rendering the use of it as a trade-off. "Nothing is absolute" is a common response $(n=6)$ from older interviewees (above 35 years old) on the issue of privacy. "There is no absolute freedom" Cuiping, a bank manager said, "A society is filled with more and more people and thoughts, facing a pandemic like this, how to manage them if freedom is absolute?" Some people consider using Health Code as a trade-off between privacy and personal safety. As Qiangzi put explicitly, "It's not really a time to discuss privacy. Nothing matters when it comes to life." Others consider the trade-off as being between privacy and collective safety. Haiyan further elaborated:

Health Code is an invasion of individual privacy. However, we do not know much about the virus, how to treat or prevent it. It is reasonable in this situation to constrain mobility and collect personal data to protect $u s$, to save time (for treatment). (emphasis added)
People also consider the use of Health Code as a tradeoff between personal interest and the collective economic good. Yuejin, a retired high school biology teacher believed that "we (retired people) could stay at home forever. Yet if our country and young people stay quarantined for too long without economic activities, they will both suffer greatly." Health Code's surveillance is essential for identifying "risky" individuals and therefore liberating the "healthy" population, thereby allowing the national economy to reopen. As Aimi put, "it released the society's mobility and productivity, so we as a society could go back to normal."

\section{Privacy fatalism}

A more cynical response to the privacy concern is what we call "privacy fatalism," a belief that privacy concerns are irrelevant because people cannot and will not have privacy in China in the era of Big Data. This fatalism is a response to the power nexus of the authoritarian state and surveillance capitalism of large technology corporations. Many interviewees believed there was simply no need to discuss the privacy problem of contact tracing at all when probed by the interviewer about their concern on privacy of Health Code. Aimi, an avid supporter of the Health Code, argued that "worries about privacy are useless. Why? Because in China no one has privacy. Health Code will not be the last straw that crushes the camel."

The Chinese government has imposed a variety of intensive surveillance and censorship systems on its citizens (Hou, 2017; Liang and Chang, 2006; Liu, 2019). Public monitors are prevalent in urban spaces. One needs to use their ID card for practically all civic activities, from purchasing a long-distance bus ticket to booking a hotel room. Using the Chinese internet demands use of your real name. Runze, a journalist locked down in his hometown of Hubei, therefore did not hesitate to submit all information requested by Health Code and was unsurprised when the police immediately contacted him by phone and then went to his home for information checking. "There are no new problems here [...] everyone is naked now; you just simply don't have privacy in front of this state. [...] What's the point of worry when you cannot change it?"

Meanwhile, the intensive surveillance of citizens by large technology companies before the pandemic also generated fatalism. Alibaba and Tencent, the two most influential technology companies in China, have huge user bases and thus influence in every aspect of Chinese life (Chen et al., 2018). As Haiyan joked, "It is impossible to not using them. They did give me lots of convenience. I cannot uninstall them all and live like a primate." The Chinese government's relatively weak 
legislation and enforcement of public data privacy protections has fueled frenzied collection of personal data. People are accustomed to it and, more importantly, are unable to contest it. As Jianguo mentioned, "Alibaba and Tencent are so powerful like monsters. An individual is powerless in front of them."

\section{Privacy protectionism}

Although almost all interviewees express some degree of dissatisfaction with Health Code's surveillance, most of them make sense of it either through tradeoffism or fatalism. Only a small fraction $(n=5)$ outright refuses to justify its invasion of privacy. Sociodemographically, these people are mostly below 30, live in big cities (Beijing, Shanghai, and Guangzhou), have been educated at elite institutions, and often have studied abroad. Their responses to the indifference or defenses of the surveillance from Health Code by others vary. For example, When Wutong was asked "why should a good person care about privacy" - a common response from the people who are indifferent to this issue - he joked, "It's like people have to use the toilet. It's normal and nothing wrong but I just don't want the world to know where I shit." Ningning argued, "it is like watching porn - of course, it is not bad, but do you want others to know your Pornhub browse history?" These positions did not necessarily exist before Health Code was released - some were realized and articulated alongside its implementation. For example, Jianguo thought:

Health Code brought the state's surveillance system from the background to the front. In the past, it looks at you silently. Wherever you go and whatever you say, some kinds of surveillance are there. Yet the surveillance became the front stage now (during the use of the Health Code), and you have to accept it to maintain the normal social interactions [...] this makes me feel quite uncomfortable.

The quick deployment of the Health Code materializes and discursively emphasizes the previously hidden surveillance infrastructures in China. It explicitly highlights the data harvesting and analytic capacity of the state. For many people, Health Code triggered a realization of the state's facility for collecting private data and the significance this holds for everyday life. While the state of emergency temporarily limits some of Health Code's more quotidian effects, it nevertheless solicits reflection among people about how life and society have changed from before the pandemic to after it. As Pingping expressed, "In the past at least the government collect your data behind you back, now they are doing this in front of your face, and who knows what will happen next?"

\section{Not (that) private}

The three subsections above show people's different sense-making processes regarding Health Code's invasion of privacy. Yet, for some, data collected by Health Code is considered general information insufficiently private to warrant protection. Some interviewees, particularly older ones, say that it does not matter that Health Code collects this data as a leak would be inconsequential to them. Caixia, a community government staffer expressed this idea:

Interviewer: Do you think there are some privacy issues here?

Caixia: I don't think so! Privacy ... I am just a laobaixing (normal person), what are things I don't want others to know? I am not a famous person or something.

Interviewer: How about data leaking?

Caixia: That's for rich or famous people, we laobaixing have nothing to leak!

Interviewer: Have you ever received any fraud message with your accurate personal information or something? Caixia: Yes, but if you don't covet things you don't deserve, then you should not fall into fraud.

Such strong indifference of personal data is rare among young people. Yet many young people also believe the data Health Code collected is disconnected from the reality of privacy, highlighting the variety of the data it collected. Ningning, for example, argued that "it (data) is just a record of my location, but it does not know what I was doing at that location, so it's not privacy." For similar reasons, many people believe the "big data surveillance" (Lyon, 2018) of the Health Code is not actual surveillance. Ningning was very cautious about privacy, yet she hesitated in calling Health Code a surveillance system: "surveillance is like... having a person behind a monitor that specifically stares at me for 360 degrees." Lingling expressed a similar idea, "surveillance is like it is looking at me specifically, yet this kind of big data does not focus on me but a group of people, so that feels very different."

Indeed, the boundary between private and general information is not absolute or fixed. Nor is it considered a binary. Many people define privacy as personal data that could be used to harm them. The critical reason why the variety of the data matters is that only certain data can be used for other, consequential purposes. As Dawei expressed, "I don't think the location data is privacy - what's the harm I can receive from these?" Yet, when we discussed the facial data 
that some Health Code systems collect, he was more concerned: "I heard that frauds could use your facial data to apply for loans from different financial APPs, that would be very dangerous. So that's privacy."

Yet merging different databases allows data of seemingly limited variety to be combined into a thick bundle that opens new possibilities for problems and profiteering, transforming "non-private" information into information directly pertaining to privacy concerns. For many, this concern applied to private companies specifically. As Ningning said:

It is just unsafe for companies to have too much data. At least the state just collects data without using them (for other purposes). Yet companies collect, sell, and combine different databases to harass you constantly. [...] All the private companies are interconnected, and I don't know where my data in one APP will be shared to another and form a full profile of myself.

Depending on who is using it, and how it is used, the same information could be considered as private and non-private simultaneously. When personal information is collected, people like Ningning admitted they preferred to have this data collected by the state than private companies. Huadong expressed caution about a government power expansion, yet ultimately admitted that:

It feels different if this information is handed to the government, at least it will not use my data to sell stuff [...] Companies are so unreliable. We often get some spam messages or phones with our personal information used; I believe most of them are leaked from different companies.

\section{Making sense of technology}

\section{Trust in technology}

"It is big data!" was the common refrain $(n=13)$ when we asked, "how do you think the Health Code determines your risk status?" Yet for our inevitable followup question - "what is big data?" - drew long pauses, hesitation, and uncertain answers like "just...big data?" Clearly, most people do not intimately understand how Health Code collects, organizes, and processes data to determine risk status. But this did not stop people from trusting and revering Health Code. As Jianguo expressed:

People are very accepting of these new things in China. Big data, AI, or cloud computing [...] they are inevitable to be used and are in fact dominating some aspects of our life. Also, we did see how much these technologies could do, and that explains the admiration.

Besides this generic faith in technological advancement and its promise of human flourishing, many Chinese people also perceive technology as objective and ameliorable. Problems might happen, but many give the technology the benefit of doubt. Aimi, a product manager working in the technology sector, argued that:

I don't believe the algorithms (suanfa) would misjudge. If that ever happened, it must be the problem of humans who operate it [...] algorithms execute what was programmed efficiently and never makes mistakes, human does. But mistakes could be solved, and the algorithms could be improved. Algorithms need time to optimize. After all, this was developed in such a short time.

This perceived technical objectivity is particularly favorable when compared with other solutions necessitating a greater degree of human involvement. For example, Nana believed using Health Code to collect health information to be a good choice because information is directly uploaded to the platform without a human intermediary: "It's safer compared with filling surveys and handling my data to government staff in my neighborhood, who might have a peep and invade my privacy - similar things happened before."

Trust in the technology generates a sense of safety for people who use Health Code, which accordingly enhances people's trust in it further. From the simple three-color system, people are classified as healthy and risky. The green code is not a clinical confirmation of an individual's healthiness. Nevertheless, it relieves a cognitive burden and gives the appearance of safety when the majority of a society is also green and safe. As Caixia put it "no matter if it is scientific or not, psychologically I feel safer when I see my code green and knowing people around me on the street is green." This type of mindset explains the refrain of "better safe than sorry" paraphrased by many of our interviewees, indicating a strong preference for false positives over false negatives in risk assessment from Health Code. For example, Yuejin argued:

Yes, staying at home for two weeks might be an inconvenience for those people who were misjudged. Yet we should all have a scale in our heart: is this personal inconvenience worse than letting those positive and risky people go? My city was closed because of a new outbreak. And now everyone stays at home. 
This precautionary approach further contributes to people's trust in technology and facilitates positive attitudes about the use of Health Code in the pandemic.

\section{Doubting the algorithm}

Although often promoted as a reliable technology based on Big Data and artificial intelligence, cloud computing, and blockchain, Health Code never fully discloses its mechanism. Ordinary people have only a vague idea about what kind of information Health Code collects, and an even vaguer idea about how it handles data and assesses risk. While many people trust the generic technologies that support Health Code, some also challenge it due to their experiences using it. The most common reason for doubt and mistrust is experiencing or hearing anecdotes of noteworthy algorithmic misjudgments $(n=6)$, which were common especially during the first month of release. Qiangzi was misjudged in March; it happened unexpectedly when trying to enter his residential community. Having been turned away by security, he jumped the wall to re-enter his home. When he called a government representative to appeal, they did not offer a clear reason why it happened:

I was pretty sure I didn't go anywhere risky [...] The representative said she can only help me file the appeal and wait for other staff and algorithms to check and did not tell me what was wrong or why this happened. I know I cannot go out, if I am not green then I cannot go anywhere anyway. [...] I waited and waited, until $2 \mathrm{am}$, it suddenly became green again.

The whole process was terrifying and confusing. Even after the problem was resolved, no one told him why Health Code faltered. Qiangzi is a programmer, so he was sympathetic to the existence of bugs. Yet nevertheless he admitted that he perceived Health Code as less magical and functional as a result of his experience.

For people who did not experience or hear about misjudgment incidents, they analogized from their experiences with other "big data and artificial intelligence" algorithms to challenge Health Code. When being asked about her trust in artificial intelligence used in Health Code, Lingling said that:

Big data and artificial intelligence are just bragging. After I bought something from Taobao (an online shopping website owned by Alibaba), it immediately recommended me to other similar stuff. But I just bought that thing. Why would I need the same thing right now again? [.. .] Artificial intelligence... I say it is artificial intelligently challenged.
Furthermore, people doubt the accuracy of Health Code based on the kind of data it collects. For example, Longzi traveled for business a lot, worrying that:

You cannot judge someone's risk status simply based on the place he or she went. What if he or she just passed by that place? With a mask on all the time? With a normal temperature? The Health Code is too crude, too simple, and too naïve. Quarantine based on it is a waste of time.

Like many others, she is challenging the accuracy of Health Code's algorithm based on the limited variety, and decontextualized nature, of the data it collects. As scientists found the majority of people infected with COVID-19 to be asymptomatic, more concerns were raised about how Health Code can collect data relevant for asymptomatic individuals. Runze worried that "Asymptomatic patients might not know their own status, and they have no symptoms to report on the Health Code. Health Code has no way to identify these people."

\section{Doubting the data}

Even when people believe Health Code can collect all essential data to make accurate judgments, they might still doubt and challenge Health Code based on their experiences and understanding of how the data is collected. People problematize data in two ways: false data and missing data. The problem of false data considers Health Code's heavy reliance on self-reporting. When initiating Health Code, individuals fill out an epidemiological survey that covers his/her travel history, contact history, and symptoms. Many interviewees admitted that they have input false data. Sometimes this was due to inconvenience. When traveling to another province in April, Dawei entered false information when initiating the destination's Health Code, explaining:

When I arrived, the staff started to ask you to initiate two Health Codes, one is the State Council's, and another is the Chongqing one. It was so annoying. My phone was slow, and people are lining up, so I just filled something right and made some random others up to save time.

Other times it was due to the concern of the Health Code's potential to misjudge and quarantine individuals. Every time Lisha fills in Health Code information, he hides his symptoms: "I have chronic sore throat and cough for months. Should I fill in that I have the symptoms? Of course not! If I said that who knows what will happen and how much trouble it might cause?" 
These personal experiences of worrying about others' false information reporting practices create doubt in Health Code's accuracy and general reliability. Nana expressed: "The more I use Health Code the more doubts I have. All the information was self-reported, there is no verification. People can easily choose not to upload their symptoms to it to get a green code."

Another concern is missing data. As many interviewees understood, once initiated, the main information Health Code collects are location via scanning QR codes at the entrance of various spaces. People quickly realized that inspectors at many checkpoints do not scrutinize people entering sufficiently. Feng recalled that:

The security of my office building stands at the revolving door checking people's Health Code. In the morning, most people must go through the same door, so it was always overcrowded. The security cannot handle so many people at the same time so he will just let people go.

Sometimes the checking is just relational. Lulu, for example, found out that "it depends on how familiar you are with the security [...] if you speak Shanghai dialect to the security (of her resident community), you can just go without having your Health Code checked."

Alternatively, people attempt to game Health Code's surveillance, such as using green screenshots (of either themselves or another person) to pass checkpoints without launching Health Code itself. These easy bypasses further undermine people's faith in Health Code's accuracy. Ningning said "it cannot trace everyone all the time and thus will not work as it claimed. It just offers some false confidence." These two kinds of doubt about Health Code data are interconnected. Aimi took a bus in April and found the bus driver did not really check her Health Code. She asked why, to which the driver responded, "What's the point for doing this? People made the information up." The perception of the false data is interconnected with the practice that results in missing data, creating a vicious loop of mistrust in Health Code data.

\section{Making sense of implementation}

\section{Paternalistic intervention}

People's trust and mistrust in the Health Code is not only about how it detects risk but also how it is implemented. The first part of the implementation considers how surveillance measures ensure data is collected and analyzed. The second part is about what comes next after a risk is detected: contact people who are classified as risky, enforce strict quarantine for risky individuals, and punish those who break the quarantine. Implementing Health Code meant a broader reorganization of Chinese society (Liu, 2020). For example, entry points to different spaces are either blocked or equipped with checkpoints, where inspectors stop people to check their Health Code status. People deemed risky were asked to quarantine and put under closer surveillance. Some might argue this to be an invasion of privacy and a constraint of civil liberty. But for many people, this amounted to a kind of caring paternalism. Yuejin, a retired high school teacher who kindly urged the interviewer to be careful in the US, said:

These Western countries give people too much freedom, but they also don't care about their people, you see what people got there? [...] The implementation of the Health Code also has a 'side effect' - so many outlaws are arrested because they cannot go anywhere without a Health Code!

People often used foreign polities routinely exhibiting what they considered irresponsible civic behaviors as counterexamples to China. For Yuejin and many others, use of Health Code and its corresponding social reorganization functioned to protect people, in contrast with the ineffective decentralized responses of "Western countries" - the assumed competitors for Chinese growing nationalist's "civilizational competition" imaginaries ( $\mathrm{Wu}, 2020)$. Therefore, increasing surveillance so the state can penetrate deeper into the corners of society is seen as a positive change that makes society safer, and unexpectedly strengthen Health Code as well as the regime's legitimacy.

\section{Doubting the implementation}

For many people, even if the Health Code could accurately surveil everyone and correctly assess risk status, the technology is still unreliably enforced. On the one hand, lax execution of disease control and people's gaming of the system could mean a high-risk individual freely moving around a city undetected. Linda's father mistakenly received a red code once. Yet, he was still able to enter a supermarket as "business wants everyone to get in and buy things." This incident made Linda lose confidence in Health Code, "If people didn't use this seriously enough, it is totally unreliable."

What further triggered people's dissatisfaction is when implementation of Health Code was replaced by other disease control approaches that people locally considered more effective. Ningning observed that: "Before Health Code came out, staff in the public transportation will take the real-time temperature of passengers, which is more accurate and useful. 
But now they only use this Health Code that relied on self-reported data." For Ningning and many others, Health Code seems to be gradually diverging from its stated ends of disease control. After months of zero new cases in her city, Ningning observed that "no one asked people to wear a mask, but we are still required to scan the Health Code every time and everywhere, which really makes you wonder: what is this really for?" Lisha found similar practices in her city, and worried Health Code excused a reduced level of accountability for the government. "they just set up the Health Code and only focus on its implementation, claiming that they have fulfilled all the responsibility. Whatever happened next is not their problem."

On the other hand, the extreme enforcement of disease control may also generate mistrust and doubt in Health Code. During March and April, controlling the transmission of the virus became extremely politicized. Government officials were punished if a new outbreak happened in their district. Accordingly, many local authorities used additional criteria to identify people's risk status besides Health Code. Runze's Health Code turned green while staying at home in a small town in Hubei province for the month of March. However, the local authority still demanded he stay at home as "the Health Code is green, but that was produced by 'big data.' It will still depend on local policy and interpretation to determine if one can go out." After he went to another city where he worked, people still required him to fill in extra documents and certifications to prove his "low-riskiness" beyond his green Health Code, often simply rejecting his interview requests because he was from Hubei province. These experiences significantly compromised his trust in Health Code, as the legitimacy of its risk status was denied by the same authorities who enforce it.

In addition, ethical concerns were raised about demanding a reliance on digital technology in order to move freely. Health Code excludes or adds a significant amount of inconvenience to those who do not have a smartphone, particularly poor and elderly people. Lisha's grandma cannot take the subway because she doesn't have a mobile phone to show her Health Code. Nana's grandpa stayed at home for months because she was confused about how to use Health Code, despite having a phone. She was concerned that "Some people who have to get out and now they are excluded. [...] Eventually, the Health Code only applies for people with good economic and educational status. It is discrimination."

\section{Worries about normalization}

While the state of emergency has faded as the pandemic comes under control in China, many places still enforce strict Health Code inspections, which concerns people regarding the normalization of Health Code surveillance in the post-pandemic society, alongside a routinization of expanded government power. Although claims that no freedom is absolute, people like Cuiping firmly disagree with the continued use of Health Code after the COVID-19: "If my life is not threatened by the disease, why would it be necessary to leave my trace all the time?" For those living in cities that were never impacted heavily by the pandemic, this worry is accentuated. Longzi complained when being asked about current Health Code use:

I understand when the outbreak was a problem in my city, we need to use the Health Code. But now everyone is back to work, all schools are reopened, and we haven't had any cases for months, why are we still using it? What is the data it collected really for?

Many people like Huadong worried that only the government has the power to determine when to stop using Health Code. "The government said at the beginning that this will be stopped once the pandemic is over. But it is them to define when the pandemic is over - when there are no domestic cases? When there is a vaccine?"

These worries were accelerated by Hangzhou municipal government in May, who proposed to reform Health Code for post-pandemic use. This new Health Code system sought to collect data beyond location information, such as medical records, physical examination reports, and lifestyle data such as food, drink, exercise, and sleep cycles. The proposal expanded risk classification from the crude tripartite healthy/risky colors into a more granular score-based system that quantifies people's health and subsequently ranks them. Hangzhou government's move caused huge controversies. Although it later clarified that it was just a "thought" instead of an actual plan, many suspected that this augured the system the government wants to build eventually. When being asked about the opinions on the Hangzhou Health Code, Xiangzi commented that:

The Hangzhou government was just too impatient. Look at all the government platforms in recent years, what that plan was proposing has been on the same road for a while [...] But unlike what they usually do like 'boiling frog in warm water,' they are now trying to boil the frog with boiling water directly!

These concerns about Health Code are not only about the imagined future. They interact with people's perceptions of their past experiences and their present use of Health Code. At the end of an interview, Lulu said: "now think about our life before the Health Code, you 
can only then realize how many things were already there." Feifei, a law student worried that "power is addictive to knowing and controlling everything. Now think about it, the Health Code shouldn't be used like this at the beginning." Many of them started to actively game or bypass the system to avoid being captured by it.

\section{Discussion}

In this paper, we examine how Chinese people make sense of Health Code, the algorithmic contract tracing and risk assessment sociotechnical assemblage. Echoing a growing scholarly focus on people's perception of algorithms in practice (Amelang and Bauer, 2019; Brayne and Christin, 2020; Bucher, 2017; Christin, 2017), we demonstrate how people perceive Health Code along three axes: privacy issues, technology use, and implementation. We show that people's concerns over COVID-19 contact tracing and risk assessment algorithms are multifaceted, intertwined, and dynamic. It is thus inappropriate to divide people into a simple support/reject binary for contact tracing and risk assessment, as individuals commonly have differing and contradictory stances on different aspects of it. For example, Linda trusted in the technical configuration of Health Code and was willing to trade-off her privacy for safety. Yet, this trust was lost when she found out that people do not check Health Code as diligently as they should, despite little change on the "technology-side" of Health Code.

These shifting, self-contradictory sense-making processes illustrate the multiplex, dynamic imaginaries of the algorithm as it is perceived by individuals over time. When people talk about an "algorithm," they are often talking about an algorithmic sociotechnical assemblage, engaged and entangled with diverse sociomaterial actors that contribute to its ontological status through their performances, beliefs, and interpretations (Introna, 2016; Kitchin, 2017; Seaver, 2017). The technical part of an algorithm, i.e. pre-defined codes that articulate and specify steps and procedures to assess inputs, comprise only part of what an algorithm does, how it is perceived, and what it ultimately is. None of our interviewees know how Health Code really works in this technical sense. Their perceptions of Health Code are instead a form of "algorithmic imaginary" (Bucher, 2017; Lupton and Michael, 2017), informed by a diffuse socio-cognitive process, shaped and reshaped through past experiences, daily interactions, and future anticipations, containing mystery and educated guesswork.

Building on relational sociology's emphasis on interdependent, processual analysis and its rejection of voluntarism and determinism (Bourdieu, 1998; Dépelteau,
2008; Emirbayer, 1997), we argue that people's sensemaking of algorithms is a form of relational perception. Depending on who designs or implements the algorithm, people's imagination and sense-making of the same technical solution could be dramatically different. These differences are related, but the relationship is contextual not deterministic. None of the Chinese public, Health Code, or people's perceptions and attitudes toward Health Code are predetermined, fixed, or categorically consistent. Our study shows people's sense-making of algorithms connects to their biographies and prior experiences with other algorithmic systems. It is informed by the future applications they foresee - such as how Health Code uses their data, and whether Health Code will be normalized. More importantly, making sense of algorithms is a dynamic, co-constitutive process as a diverse set of human and non-human actors form part of the algorithmic sociotechnical assemblage through interaction. We show how encounters with Health Code inspectors, other users, or smartphones effect this sense-making process. This local variability is nested in social surroundings, and broader perceptions of disease control strategies at the national and global level. For example, many people attribute a necessity to Health Code because other societies' lack an equivalent, or have controlled COVID-19 incompetently, fitting the accelerating the Chinese nationalist "civilizational competition" discourse (Wu, 2020), thereby unexpectedly legitimizing the scope of expanded surveillance and Chinese authority.

This relational and co-constitutive understanding of algorithmic sociotechnical assemblages sheds light on why many Chinese people favor state surveillance over private companies during the pandemic. The Chinese state's power matters. While the state relies on private companies' technical capacity to enforce algorithmic governance, they nevertheless exert strong control over key decision-making and agenda-setting (Fourcade and Gordon, 2020; Hou, 2017). Similar to Chinese people's high support and low concern for the new social credit systems' privacy invasions (Kostka, 2019), people's overall sense of fatalism and acceptance of Health Code's surveillance acknowledges a dearth of options of choice under the state-run compulsory system. However, this question cannot only be explained by demonstrated Chinese state coercion, overreaching cultural preference or a generalized sense of security in China as previous studies indicate (Liang and Chang, 2006; Lü, 2005; Zhang et al., 2019). We show a key factor that impacts people's perception of Health Code is not that they are being surveilled or that their privacy is being invaded, but their perception of how they are being surveilled, how the data will be used and for what purposes by which party, echoing 
scholarship outside the Chinese context (Bucher, 2017; Lupton and Michael, 2017; Zimmer et al., 2020). The surveillance and data collection of the state is considered passive, routine, bureaucratic, and thus acceptable. In contrast, private tech companies' surveillance and data collection is broadly considered intrusive, promising targeted advertising or spam, and thus more visible and liable to create antipathy among the public. These two different uses of surveillance data, derived of differing institutional logics from the state and the market, provide the substrate on which individual algorithmic imaginaries grow.

We conclude with two methodological reflections. The first is regarding conducting qualitative research on algorithms during the COVID-19. The ongoing pandemic brings many challenges, such as social distancing, forcing reliance upon digital platforms for conducting research. These platforms allow researchers to reach more people but also generate systematic limitations. We show how people's knowledge of those who are excluded by Health Code will change their perception of the system, yet our sample did not capture people who were themselves systematically marginalized, such as the elderly and technophobic. These exclusions, ironically, mirror a common criticism of Health Code. During the pandemic, digital inclusion has become more essential across a wider array of contexts (Fourcade and Gordon, 2020), requiring scholars' special attention.

The second reflection is regarding the extent of generalizability in the Chinese case. China is special in terms of its authoritarian governance regime, one-party system, prevalent censorship, etc. These "Chinese characteristics (zhongguo tese)" remain critical scholastic avenues, as we consider the sociopolitical system in China a direct facilitator for Health Code in multiple ways. But these Chinese characteristics are often caricatured in scholarship. We endorse careful empirical examination on a case-by-case basis when undergoing research on Chinese society. By doing so, we avoid Chinese exceptionalism discourse whereby dynamic reality is unfairly reduced to authoritarian determinism (Guan, 2019; Hou, 2017) - a uniformly oppressive Chinese state herding a brainwashed and lemming-like citizenry. This lens conceals more than it reveals, and also hampers the capacity to learn about other societies from experiences in China. The relational perception of privacy, technology, and implementation of Health Code we illustrate could offer critical insights into similar algorithmic regimes elsewhere. Our research presented above is in this spirit.

\section{Acknowledgements}

We are grateful to all our study participants that accepted our interviews during this difficult time. John Evans, Lilly Irani, and reviewers from Big Data \& Society offered constructive feedback, for which we are thankful. We would like to express special thanks to Marie Xu and Zhengyun Zhou, who provided great assistance in data collection.

\section{Declaration of conflicting interests}

The author(s) declared no potential conflicts of interest with respect to the research, authorship, and/or publication of this article.

\section{Funding}

The author(s) received no financial support for the research, authorship, and/or publication of this article.

\section{ORCID iDs}

Chuncheng Liu (D) https://orcid.org/0000-0001-5842-7988

Ross Graham (D) https://orcid.org/0000-0003-4578-7022

\section{References}

Alsan M, Braghieri L, Eichmeyer S, et al. (2020) Civil Liberties in Times of Crisis. Cambridge, MA: National Bureau of Economic Research.

Amelang K and Bauer S (2019) Following the algorithm: How epidemiological risk-scores do accountability. Social Studies of Science 49(4): 476-502.

Armstrong D (1995) The rise of surveillance medicine. Sociology of Health \& Illness 17(3): 393-404.

$\mathrm{Au} \mathrm{L}, \mathrm{Fu} \mathrm{Z}$ and Liu C (2020) It is (not) like the flu: Expertise and temporality in United States, China, and Hong Kong. In: Covid-19 conference, 10-11 July, 2020.

Bengio Y, Janda R, Yu YW, et al. (2020) The need for privacy with public digital contact tracing during the COVID-19 pandemic. The Lancet Digital Health 2(7): e342-e344.

Bourdieu P (1998) Practical Reason: On the Theory of Action (Trans. R Johnson). 1st ed. Stanford: Stanford University Press.

Brayne S and Christin A (2020) Technologies of crime prediction: The reception of algorithms in policing and criminal courts. Social Problems. Epub ahead of print 5 March 2020. doi: 10.1093/socpro/spaa004

Bucher T (2017) The algorithmic imaginary: Exploring the ordinary affects of Facebook algorithms. Information, Communication \& Society 20(1): 30-44.

Center for Disease Control (2020) Contact tracing. Available at: www.cdc.gov/coronavirus/2019-ncov/daily-life-coping/ contact-tracing.html (accessed 8 February 2021).

Cha V (2020) Asia's COVID-19 lessons for the west: Public goods, privacy, and social tagging. The Washington Quarterly 43(2): 1-18.

Chen Y, Mao Z and Qiu JL (2018) Super-Sticky Wechat and Chinese Society. Bingley: Emerald Publishing.

Christin A (2017) Algorithms in practice: Comparing web journalism and criminal justice. Big Data \& Society 4(2): $1-17$.

Collado-Borrell R, Escudero-Vilaplana V, Villanueva-Bueno $C$, et al. (2020) Features and functionalities of smartphone apps related to COVID-19. Journal of Medical Internet Research 22(8): e20334. 
Dépelteau F (2008) Relational thinking: A critique of codeterministic theories of structure and agency. Sociological Theory 26(1): 51-73.

Edwards L, Veale M, Lynskey O, et al. (2020) The coronavirus (safeguards) bill 2020: Proposed protections for digital interventions and in relation to immunity certificates. Preprint, 13 April. LawArXiv. DOI: 10.31228/osf.io/yc6xu

Emirbayer M (1997) Manifesto for a relational sociology. American Journal of Sociology 103(2): 281-317.

Eubanks V (2018) Automating Inequality: How High-Tech Tools Profile, Police, and Punish the Poor. New York: St. Martin's Press.

Fang TM (2020) Sending a red signal: When a contact tracing app went wrong a journalist was forced to stay in their home in China. Index on Censorship 49(2): 34-36.

Foucault M (1990) The History of Sexuality, Vol. 1: An Introduction. Reissue ed. New York: Vintage.

Fourcade M and Gordon J (2020) Learning like a state: Statecraft in the digital age. Journal of Law and Political Economy 1(1): 78-108.

Fourcade M and Healy K (2017) Seeing like a market. SocioEconomic Review 15(1): 9-29.

French M and Monahan T (2020) Dis-ease surveillance: How might surveillance studies address COVID-19? Surveillance \& Society 18(1): 1-11.

Guan T (2019) The 'authoritarian determinism' and reductionisms in China-focused political communication studies. Media, Culture \& Society 41(5): 738-750.

Hou R (2017) Neoliberal governance or digitalized autocracy? The rising market for online opinion surveillance in China. Surveillance \& Society 15(3/4): 418-424.

Ilyushina M (2020) Moscow rolls out digital tracking to enforce lockdown. Critics dub it a 'cyber Gulag'. Available at: www.cnn.com/2020/04/14/world/moscowcyber-tracking-qr-code-intl/index.html (accessed 24 August 2020).

Introna LD (2016) Algorithms, governance, and governmentality: On governing academic writing. Science, Technology, \& Human Values 41(1): 17-49.

Kitchin R (2017) Thinking critically about and researching algorithms. Information, Communication \& Society 20(1): 14-29.

Kitchin R (2020) Civil liberties or public health, or civil liberties and public health? Using surveillance technologies to tackle the spread of COVID-19. Space and Polity 24(3): 362-381

Knorr Cetina K (1999) Epistemic Cultures: How the Sciences Make Knowledge. Cambridge: Harvard University Press.

Kostka G (2019) China's social credit systems and public opinion: Explaining high levels of approval. New Media \& Society 21(7): 1565-1593.

Liang $\mathrm{G}$ and Chang $\mathrm{H}$ (2006) Surveillance and privacy in urban China. Available at: www.sscqueens.org/sites/ sscqueens.org/files/China_Report_March_07.pdf (accessed 8 February 2021).
Liu C (2019) Multiple social credit systems in China. Economic Sociology: The European Electronic Newsletter 21(1): 22-32.

Liu C (2020) Algorithms in action: Reassembling contact tracing and risk assessment during the covid-19 pandemic in China. SocArXiv. DOI: 10/ghcwnx.

Loder E (2020) Getting it right in the pandemic. BMJ 370: $\mathrm{m} 2637$.

Lü Y-H (2005) Privacy and data privacy issues in contemporary China. Ethics and Information Technology 7(1): 7-15.

Lupton D and Michael M (2017) 'Depends on who's got the data': Public understandings of personal digital dataveillance. Surveillance \& Society 15(2): 254-268.

Lyon D (2018) The Culture of Surveillance: Watching as a Way of Life. 1st ed. Cambridge, UK: Polity.

Mittelstadt BD, Allo P, Taddeo M, et al. (2016) The ethics of algorithms: Mapping the debate. Big Data \& Society 3(2): $1-21$.

Nielsen N (2020) Privacy issues arise as governments track virus. Available at: https://euobserver.com/coronavirus/ 147828 (accessed 24 August 2020).

Pasquale F (2015) The Black Box Society: The Secret Algorithms That Control Money and Information. Cambridge: Harvard University Press.

Rona-Tas A (2020) Predicting the future: Art and algorithms. Socio-Economic Review 18(3): 893-911.

Seaver N (2017) Algorithms as culture: Some tactics for the ethnography of algorithmic systems. Big Data \& Society 4(2): $1-12$.

Shao C (2020) The Surveillance Experience of Chinese University Students and the Value of Privacy in the Surveillance Society. Chapel Hill: University of North Carolina.

Tang Q (2020) Privacy-preserving contact tracing: Current solutions and open questions. arXiv:2004.06818 [cs]. Available at: http://arxiv.org/abs/2004.06818 (accessed 10 August 2020).

Timmermans S and Tavory I (2012) Theory construction in qualitative research: From grounded theory to abductive analysis. Sociological Theory 30(3): 167-186.

Wu AX (2020) The evolution of regime imaginaries on the Chinese Internet. Journal of Political Ideologies 25(2): 139-161.

Zhang H, Guo J, Deng C, et al. (2019) Can video surveillance systems promote the perception of safety? Evidence from surveys on residents in Beijing, China. Sustainability 11(6): 1595.

Zimmer M, Kumar P, Vitak J, et al. (2020) 'There's nothing really they can do with this information': Unpacking how users manage privacy boundaries for personal fitness information. Information, Communication \& Society 23(7): 1020-1037.

Zuboff S (2019) The Age of Surveillance Capitalism: The Fight for a Human Future at the New Frontier of Power. 1st ed. New York: Public Affairs. 